\title{
A survey of social media use in emergency situations: a literature review
}

\section{Najeeb Gambo Abdulhamid}

Jigawa State Polytechnic Dutse

\section{Daniel Azerikatoa Ayoung}

Bolgatanga Polytechnic

\author{
Armin Kashefi \\ Brunel University
}

\begin{abstract}
This study reviews literature on the use of Social Media (SM) in emergency response operations while identifying gaps in this research stream that need attention from Information Systems (IS) researchers. The research is grounded in past works and attempts to build on research on the application of SM in emergencies. It focuses on understanding the role of SM in the prevention, management and response to emergencies. The review contains a detailed literature exposition of IS and disasters journals. The appraisal of such research stream led the review to focus on the concept of digital volunteerism as an offshoot of crowdsourcing initiatives. Findings from the review reveal that previous studies overlooked the interfacing challenges between formal and traditional aid agencies on one hand and digital humanitarians on the other. Consequently, we identify gaps in the extant literature and propose areas of interest for future research.
\end{abstract}

Keywords: social media, humanitarian emergencies, information systems, digital volunteers, crowdsourcing

Corresponding author: Dr Najeeb Gambo Abdulhamid, Department of Computer Science, Jigawa State Polytechnic Dutse, Nigeria. Email: aagambo@jigpoly.edu.ng

\section{Introduction}


The study focuses on understanding the role of social media in crises. Social media platforms have the potential for creating instantaneous replication mechanisms with continuous cycles of information distribution (Wattal et al., 2010). It is inexpensive, easy to use and has the tendency of raising global awareness coupled with the potential of enhancing social capital, connections and fostering community resilience (Houston et al., 2015). Social media is recognised for its immediacy and pulsation effect (McGrath et al., 2012) as well as its potential for casting a global spotlight on hitherto remote communities. Such possibilities for replication, immediacy and pulsation, of throwing global spotlight and of fostering community resilience are some of the most desired potentials required in any high-velocity environment like disasters. Such possibilities and the nature of the phenomena and its application in the emergency realm is what provides a window for IS scholars to be interested and became essential stakeholders to investigate the social media phenomena during emergencies. As a result of the pervasive nature of SM and its subsequent application in crises, several scholars have investigated and reported on its influence in emergency contexts. Regardless of the significant number of literature in this area, Fraustino, Liu and Jin (2012) suggest that researchers correspondingly need to focus on the synthesis of what has been done so far. It is in these syntheses that we are able to establish the link between SM and disaster effort due to the broad and longer-term perspective of ICTs and emergency response. Thus, the review is timely, given the growing global application of various SM tools in crisis response. This study is therefore, aimed at providing insight to the following research questions:

- What does the existing research evidence tell us about Social Media use in emergency management?

- What gaps exist in the current literature?

The following review discusses the nature of the uses of social media during emergency response operations. It also critically appraises the nature of social media and later, explores some unintended consequences of the use of social media in complex situations.

\section{Method}

Using the interpretivist approach as a method of qualitative inquiry, we conducted our literature review following Vom Brocke et al. (2015) 'recommendations of literature search in Information Systems research'. Our basis of doing so stemmed from the fact that research blossoms when scholars reuse the methods and knowledge developed by peers (Jomier, 2017). As a result, we combine Luna and Pennock's (2018) and Reuter and Kaufhold (2018) approach to a literature review. In combining the two methods as our prescriptive lens for reviewing past studies, we begin with Luna and Pennock's (2018) approach. It began with conceptualising the social media definition, then identifying source of literature such as scientific literature, official literature and specialised literature. Scientific literature involves studies from journals, conference proceedings and books. Official literature 
comprises government document, policies, training manuals and official reports among others. Specialised sources are studies obtained from journals such as, International Journal of Mass Emergencies and Disasters (IJMEDS) as well as Information Systems for Crisis Response and Management (ISCRAM). Next, the authors identified key search terms such as 'social media', 'crisis response', 'emergency management', 'disaster response' among others. Later, we followed Reuter and Kaufhold (2018) methodology of identifying previous case studies on the use of social media in emergencies. In their studies, the authors focus was on specific events in which they later summarised trends across different type of events. Next, the authors explored the type of research in each case study and finally classify the studies into categories of interaction studied and derived use pattern.

\section{Search terms}

Our choice of databases for our literature search was informed by Wolfswinkel, Furtmueller and Wilderom's (2013) methodological approach where we limited our work to the use of electronic journals. As a result, we restricted our search to Wiley-Blackwell Full Collection (1997 to date), Elsevier (Science Direct), Business Source Premier and Palgrave McMillan databases for two reasons. First, these databases have more comprehensive collection coverage. For example, the Business Source Premier we have access to have collections dating back to 1997 while that of Palgrave McMillan databases collections started from 1991 to the current date of our literature search. Second, these databases are the ones we had access to at the time of our work.

As with all other studies, our choice of key terms was inspired by the first title of our first author's thesis on the use of social media in disasters and emergencies. Later, we were inspired by Kaplan and Haenlein's (2010) classification of social media in which they based their work using 'social presence/media richness' and 'self-presentation/self-disclosure'. It was this classification that gave us a clue on our initial search. Against this, our search was limited to the dimensions that were popularised by Kaplan and Haenlein (2010). Hence, the combinations of the following search terms were used to form the search string; 'Twitter', 'OpenStreetMap', 'Facebook', 'YouTube', 'Instagram', 'social media', 'web 2.0', 'digital media', 'social network' 'crowdsourcing', 'crowdfunding' and 'digital humanitarian'. The study after the initial search adopted variations of the following search string to incorporate all the key terms mentioned above for the study: Use of social media during disaster emergencies. The search was restricted to resources published between 2000 and 2015 and reviewed literature around concepts/themes in the domain of social media use in emergencies. Our search ceased when returns seemed not to add relevant articles (Webster and Watson, 2002). The review was primarily concept driven but also made room for articles which were theory specific. The essence of adopting multiple sources was to ensure that relevant articles were not missed.

\section{Resources searched}


Our initial search for relevant literature involved vital information sources. To ensure a sound and well-grounded review process to advance knowledge (Webster and Watson, 2002), we employed the use of scholarly peer-reviewed journals for the apparent reason that these journals usually contain contributions that are most likely of a high standard (See Appendix A). It is worth noting that we also searched and included grey literature from reputable sources relevant to the disaster and emergency field.

\section{Search process}

The search was conducted between January 2015 and September 2016. A standardised search strategy was used with few modifications consistent with the type of source being searched. For example, some databases provide search options likes 'all text', 'author', 'title', 'subject', 'abstract/authorsupplied abstract', 'Author-supplied keywords', and 'optional'. These options produce different output depending on the database a researcher is using. As an example, when we used 'social media' as a search string in Business Source Premier, using 'all text' parameter, the resulting output produced 67 results.

On the other hand, while we restricted our search by using the 'title' parameter, the output produced only five (5) results. As a result, we adopted a three-step search approach to collect the most relevant articles possible for the review. In the first instance, we opted to start the search process with two renowned Information Systems journals namely; Management Information Systems Quarterly (MISQ) and European Journal of Information Systems (EJIS). Subsequently, we added the Information Systems Frontiers and Journal of Information Science and then later, expanded to other journals.

After the preliminary search, we identified articles on social media use in emergencies as defined by this study. At the second stage, the selected papers were categorised according to thematic areas around the research objectives (Braun and Clarke, 2006). The first author manually evaluated all the titles, abstracts and keywords of articles returned to be able to include or exclude such papers.

Selected articles were then passed on to the second and third authors to retrieve full articles for a detailed review and subsequent analysis. In this study bibliographies of selected articles were not searched for candidate papers (Van Der Meijden et al., 2003). The report of the findings focuses mainly on the uses and impact of this socio-technological phenomenon during emergencies. Also, apart from reporting the use of SM in emergencies, emerging themes are also discussed.

\section{Inclusion/exclusion criteria}

Results returned from the searches were evaluated against a set of inclusion and exclusion criteria. We restricted our selection process to include only electronic/digital libraries/journals, articles published only in English; search results that did not return or grant access to the full article were excluded.

The next section discusses our findings. 


\section{Results}

This review contains 49 publications which start from 2002 to 2016. Nonetheless, we incorporated a seminal paper from 1957 that provides insights into the sociology of convergence behaviour by emergent groups during disasters (Fritz and Mathewson, 1957). The article offers unique insight into the different type of routines alongside their motivations. The authors suggest convergence behaviour is spontaneous and informal as well as taking the form of movement of people, messages and supplies towards disaster areas. From our review, the year 2014 appeared to be a year with highest publications whose central themes revolved around crowdsourcing (Boughzala and Vreede, 2014; Liu, 2014; Poblet, Garca-Cuesta and Casanovas, 2014) on the one hand and understanding digital volunteers, their uses as well as barriers of coordinating their work with emergency management organisation (Van Gorp, 2014; Hiltz, Kushama and Plotnick, 2014; Jung and Moro, 2014; Jung and Park, 2014; Morris, 2014; Panagiotopoulos, Bigdeli and Sams, 2014). Our guess is, these themes become more pronounced because of the near maturity of social media in the disaster research field. Furthermore, 2011 featured eight publications in which the focus of the study as at that time revolved around understanding crowdsourcing in emergencies (Doan, Ramakrishnan and Halevy, 2011; Geiger et al., 2011) and investigating the use of Twitter by emergent groups (Bright, 2011; Cheong and Lee, 2011; Oh, Agrawal and Rao, 2011; Starbird and Palen, 2011). In our estimation, the attention given to crowd work might be as a result of the rising needs for understanding its application beyond the sphere of traditional open calls. Likewise, the growing interest of researchers to study the use and application of Twitter could be attributed to many affordances and ease of use associated with Twitter.

From the 49 papers we included in our review, 27 are published as journal papers, and 16 as conference papers. The remainder include a blog entry, magazines, newspaper as well as special reports. Most of the documents we reviewed are qualitative and employ a range of data collection methods. The coded results were grouped around different areas of impact and further examined for the following overarching trends: users and uses of social media, social media drawbacks and its affordances, crowdfunding, crowdsourcing and its use in emergencies as well as digital volunteerism.

\section{Social media in emergencies}

Our review of the literature on the use of social media in emergencies shows that previous studies tended to cluster around three broad themes. These themes include information sharing, situational awareness for decision making and collaboration among citizens, emergency management organisations, aid agencies as well as digital volunteers. For example, a review of past studies identifies social media users during emergencies as individuals, communities, private and public organisations as well as media outlets (Jung and Moro 2014). Fraustino, Liu and Jin (2012), as well as Morris (2014), went beyond understanding its use but sought out to find why they are using it at an individual level? The authors argue that people use social media because of convenience, as well as 
looking for emotional support and healing. Other reasons include checking in with family and selfmobilisation (ibid). Several scholars suggest that people use social media during emergencies for organising and receiving emergency preparedness information and notices, signalling and detecting crises before it happens as well as reconnecting a community and its displaced members. Other findings revealed convenience and social norms, self-mobilisation, and connecting to those in situations of emergency or act as a stress release (Fraustino, Liu and Jin, 2012; Jung and Moro, 2014).

Social media provides aid workers, disaster-affected communities and anyone with access to the Internet the opportunity to gather, extract, visualise and chronicle what is happening during emergencies (Cheong and Lee, 2011; Jung and Park, 2014). For example, humanitarian response organisations are taking advantage of social media for enhancing their situational awareness $(\mathrm{Oh}$, Agrawal and Rao, 2011). To put it differently, social media platforms can enable emergency workers swift decision-making process in a high-velocity environment through enhancing their situational awareness and responsive gathering of real-time data.

Various studies show that governmental organisations and aid agencies make use of social media during emergencies to share information and communicate with citizens (Bright, 2011; Cheong and Lee, 2011; Chatfield, Scholl and Brajawidagda, 2013). For example, during the Christmas season of 2010, the national Swedish train operator takes advantage of Twitter to communicate to passengers and answer their queries (Larsson and Ågerfalk, 2013). Also, during the 2011 England riot, various local government councils made use of Twitter to collaborate with the citizens in dousing the tension and organising for clean-up (Panagiotopoulos, Bigdeli and Sams, 2014).

Further review of past studies reveals a mixed finding on social media potentials and pitfalls (Putnam 2002; Mills et al. 2009). Recent research carried out by Panagiotopoulos et al. (2014), and Morris (2014) strengthened such dualities. Putnam (2002), for example, revealed that social media could serve as a potent tool for decision making, for conveying glad tidings about the safety of loved ones as well as a resource for preparedness and training purposes. Mills et al.s' (2009) study describes Twitter as a tool that is particularly useful for providing real-time and integrated information in an unprecedented manner not covered via radio and television. The finding concludes that there is no technology capable of competing with it. Likewise, Panagiotopoulos et al.s' (2014) study on the organising role of social media in the context of 2011 riots in the United Kingdom (UK) affirms that social media can enable partnership and interaction between government and community. The study analysed 1746 Twitter dataset posted by 81 local governments and reveals that the conversational nature of Twitter proves how it can serve as an anchor for organising. However, Putnam (2002), Mills et al. (2009) and Panagiotopoulos et al. (2014) conclude their study with a caveat. Putnam states that empirical evidence suggests that it was also a medium for spreading misinformation that was capable of undermining aid work. He further cautioned that the next challenge for humanitarian managers is to 
save social media from becoming part of the emergency. In other words, it must be part of the emergency work plan. This is in line with Mills et al.s' (2009) suggestion that the technology is not yet ripe for a robust emergency communications system. It is not, however, useful for management purpose in emergencies. The study nevertheless recommends its usage for mitigation purposes in detecting the thought of affected communities and finding information by the civilian population. The research further raises doubt about its potential as a complementary tool for an emergency operation.

Against this background, it is reasonable to agree with their criticisms in part and disagree with some. The reason is, Panagiotopoulos et al.'s (2014) study show that social media platforms enabled flash mobs that led to the 2011 riots in different parts of England. Surprisingly, some studies proved otherwise. Contrary to such assertion, there is no significant evidence for linking such a claim of using social media during the said riot. Conversely, there was substantial "evidence", according to a study that looked at 2.4 million tweets sent, to suggest the use of Twitter and other social media outlets in mobilising support for the post-riot clean-up activities. The study concludes that protesters used Blackberry messaging apps extensively to assemble and share information in advance (Bright, 2011; Lewis et al., 2011). Past studies also examine both the perception and credibility of information shared via Twitter. So also do Nogami and Yoshida's (2014) survey on the effects of information sources on belief related to disaster myths among Japanese. The study conducted by Oeldorf-Hirsch and Schmierbach (2012) evaluates news from Twitter posts and compares it with news shared from the main source with a view to understanding how Twitter influences perceptions of information. The findings indicate that even regular users of the microblogging tools do not see it as a platform for providing information that is more reliable. The study recommends the need for caution in the use of a microblogging tool as a way of distributing information. Even though Oeldorf-Hirsch and Schmierbach end with a word of caution, Nogami and Yoshida's (2014) conclusion sees it differently. According to the latter, recent happenings prove that social media immediacy and pulsation effect have the potentials of concealing fallacies and misinformation.

Interestingly, Zhiwei, Jian and Wangchen (2015, p. 369) provide additional support to the above thesis, in a study in which they examine how rumours spread over social media using a multi-layered communication model. Their finding shows that people spread rumours "based on three factors: the opinion environment, the individual's social influence, and the cost to confirm the information". Moreover, their result demonstrates that the same rumour could stop because of the interaction that occurs in the social fabric. Overall, their discovery proves how in practice in promoting web 2.0 could help the social structure to accelerate rumour stopping.

Palen, Vieweg and Anderson (2010) argue that when the need for help is at its peak, it is a delusion to trust that anyone has flawlessly accurate information. In such critical circumstances, it is hard to 
account for the whole of the event. If someone claimed that, there is no way to categorise such events as a disaster situation. However, in a counterargument, the authors opined that technical support could facilitate the collation and injection of metadata, which frontline workers must make to assess credibility and helpfulness. In other words, "people's assessment of information helpfulness and credibility is a function of the "everyday analytic" (p.52). They therefore conclude it is not the job of the services and tools to make decisions; instead, allow their frontline workers to conclude as hurriedly and confidently as possible. In brief, social media studies provide mixed findings, where some established its usefulness and others documented challenges.

While the above paragraphs reviewed the uses of social media, other scholars such as Fraustino, Liu and Jin (2012) claimed privacy concern, security, and accessibility issue as the primary fundamental reasons preventing people from using social media during emergencies. Other scholars claimed that some government officials are using social media in emergencies without formal training and understanding its implication. Furthermore, other findings revealed lack of time, policies and guidelines and concern about the trustworthiness of the social media data are among the foremost barriers (Hiltz, Kushama and Plotnick, 2014). This is in addition to the lack of archiving tools to curate information generated during crisis through social media platforms (Fraustino, Liu and Jin, 2012). Nonetheless, Tapia and Moore (2014) argue that "emergency responders already operate with less than reliable, or "good enough," information in offline practice, and that social media data are useful to responders, but only in specific crises". Also, the study shows that aversion to the use of social media by emergency organisations transcends data quality and trustworthiness issues but revolves around the operational concern. In a separate study (Tapia, Moore and Johnson, 2013), the authors explained where social media data are useful to responders. Findings from this study, involving representatives from an international response organisation, suggest that crowdsourced social media data is more useful at the inception of response operations, on the areas of supply management, and "when the risks of ignoring an accurate response outweigh the risks of acting on an incorrect one". Other scenarios where crowdsourced information may not be considered include search and rescue operations (Tapia, Moore and Johnson, 2013).

Other studies related to social media involve development of frameworks and models. For example, Jung and Moro (2014) identified five multilevel functionalities of social media by individuals, organisations, government and mass media which include micro, meso, macro, cross-level, and direct channels which is between micro/meso and macro level. Also, Houston et al. (2015) develop a framework for users and uses of social media.

In summary, this subsection reviews past studies on the use, users, challenges and drawbacks of using social media in emergency situations.

\section{Crowd work}


This subsection addresses studies related to the application of social media in crowdfunding and crowdsourcing.

Crowdfunding, as understood in this review, refers to an open call by an individual, or entity - social, cultural, ideological, or for-profit groups - to the public to raise funds via any ICT-based platform for a specific purpose (Najah and Jarboui, 2015). In other words, it is a process of using the onlinedistributed crowd to generate funding for a cause(s) which can take the form of providing help to disaster victims.

Extant literature associated with crowdfunding has so far examined the relevance and challenges of web 2.0 in fundraising. For instance, Boeder's (2002) study on the significance of web 2.0 for a nonprofit organisation shows that it enables a versatile platform for advocacy, creative sharing of ideas, and fundraising. Findings also reveal web 2.0 as a critical information infrastructure that provides new tools and promising opportunities for driving and facilitating positive change in the community like providing help to disaster victims. Similarly, research conducted by Stiver et al. (2015) on online crowdfunding for civic projects further testifies to the potential of social media in providing a platform for securing funds and completing projects. The study also reveals the potential of web 2.0, that can enable organisations to forge a partnership between and across government agencies, businesses, and citizens.

From the available studies in IS Journals, crowdfunding for disasters has not been given much attention from both IS and the disasters community. What is surprising is that social media and other traditional sources are replete with testimonies and high-sounding stories on how one organisation or the other generated funding. For example, in less than 24 hours, J.J. Watt was able to raise more than $\$ 10,000$ on the GoFund me platform ${ }^{1}$. However, such knowledge seems to elude scholarly peerreviewed journals. There is, therefore, a clear literature gap that needs urgent attention from IS researchers.

Next, we review papers that examined concepts, taxonomies, components, and functions of crowdsourcing. Following that, we move on to review foundation studies on crowdsourcing and then narrow the focus to research related to the volunteer and technical communities (V\&TCs).

Based on our review, previous studies related to crowdsourcing in disasters clustered around understanding its definitions, classifications, models, framework, motivation, as well as its application in emergencies and crisis. For example, since Howe's (2006) coinage of the term from 'crowd' and

1

https://www.gofundme.com/f/victimsofhurricaneharvey?utm source=prnewswire\&utm medium=referral\&utm content=hur ricane-harvey\&utm campaign=Press 
'outsourcing', crowdsourcing has been defined by several authors including Estellés-Arolas and González-Ladró n-de-Guevara (2012) and Hetmank (2013). In trying to provide a comprehensive definition of crowdsourcing, Hetmank (2013) synthesised several papers and identified 17 different meanings which the author later categorised in four dimensions, organisational, technical, functional and human-centric (Hetmank, 2013). A more nuanced definition was provided by Liu (2014) in which the author defines crowdsourcing as a "dynamic form of cooperative work involving a large and often indeterminate number of civic participants conducting semi-autonomous tasks to address information management issues. This type of mass collaboration typically occurs in a distributed way often leveraging social networking technologies to facilitate coordination among different crowds ( $p$. 390)".

On the other hand, Starbird (2012) calls for an alternative view of conceptualising crowd work. According to him, various studies approached crowd work with different names such as 'crowdsourcing', 'collective intelligence' or 'human computation' in disasters. The author concludes that "In every case, within the context of disaster, crowd work takes the form of organising information and organising people to organise information." (p. 8). Table 1 provides a synthesis of other crowdsourcing names.

Table 1: Synthesis of other names for crowdsourcing

\begin{tabular}{|l|l|}
\hline Other names of crowdsourcing & Authors \\
\hline Collective intelligence & Thuan, Antunes and Johnstone, 2015; Warr, 2008 \\
\hline Open innovation & Marjanovic, Fry and Chataway, 2012 \\
\hline Collective wisdom & $\begin{array}{l}\text { Doan, Ramakrishnan and Halevy, 2011; Hwang, } \\
\text { Yuan and Weng, 2011 }\end{array}$ \\
\hline Crowd work & Ramakrishnan and Halevy 2011, Kittur et al. 2013 \\
\hline Peer Production & Haythornthwaite, 2009 \\
\hline Smart Mobs & Rheingold, 2007 \\
\hline Co-Creation & Zwass, 2010; Kohler et al., 2011 \\
\hline
\end{tabular}

Other studies dwelled on providing various classifications/taxonomies of crowdsourcing (Doan, Ramakrishnan and Halevy, 2011; Geiger et al., 2011), while others offer insight into the types of tools and platforms associated with crowdsourcing (Poblet, Garca-Cuesta and Casanovas, 2014). In the latter study, the authors (ibid) explore the kind of web-based tools and platforms for crowdsourcing during emergency response operations. The research proposed a taxonomy of such devices and platforms. Besides, other authors reviewed earlier studies and came up with different crowdsourcing model and frameworks. For instance, Haythornthwaite (2009) proposed two types of crowdsourcing 
models - lightweight and heavyweight, while Boughzala and Vreede (2014) proposed a model and named it as Crowdsourcing Ideation Maturity Assessment Model (CIMAM). Also, using the concept of 'articulation of work' as an analytic frame, Liu (2014) study provides a salient dimension of crisis crowdsourcing. The framework offers a lens for understanding the why, who, what, where, when and how of an aspect of crowdsourcing alongside social, technological, organisational and policy interfaces associated with the 'articulation work'. Other authors proposed a community-based framework for crowdsourcing tasks during disasters to managing registration and task distribution using multiple social contexts (Yu et al., 2012).

On what motivates people to crowdsource, previous studies identify altruism, location factor, experience gathering and research, among others as motivation to participate in crowdsourcing (Brabham, 2012). Moreover, other studies highlight the use of crowdsourcing to provide information as a form of aid (Heinzelman and Waters, 2010).

\section{Digital volunteers}

This review began with an exposition on the use of social media in emergencies. Then we showed that the adoption of social media stimulates the birth of crowdfunding and crowdsourcing. We will now discuss how crowdsourcing phenomena spurred the emergence of online volunteer groups. Unlike the previous section, that draws literature mainly from IS and disasters journals, this segment will bring references from organisational studies and sociology of disaster scholars. In this section, the review provides a critical appraisal of organised response, collective behaviour, as well as debate and issues associated with humanitarian intervention.

\section{Emergent volunteer groups}

Historically, the use of crowdsourcing in situations of crisis began with the online convergence of bystander volunteers who use mobile technologies and web-based applications to raise awareness and solicit support for the affected communities (Campbell, 2010). Earlier traces of such activities by these disparate online volunteers were during the 2004 Indian Ocean Earthquake and Tsunami, and the 2005 London bombing, as well as Hurricane Katrina (Starbird, Muzny and Palen, 2012). During such periods, volunteers used Flickr to rally support for the disaster-affected communities (Liu et al., 2008). Moreover, some additional evidence of the applications of crowdsourcing to situations of crisis using social media platforms such as Blogs and Facebook was seen during Hurricane Katrina in 2005 and the Virginia Technology shooting in 2007 (Vieweg et al., 2008). Such platforms served as tools for collective intelligence by these online volunteers to maintain a sense of community. These platforms were also helpful in finding missing persons and identifying victims. Vieweg et al. (2008) opined that during the Virginia Tech shooting, these volunteers used Facebook to identify most of the victims ahead of the official pronouncement by the College. 
Long before the advent of web 2.0, disaster sociologists provided a sociological explanation of how people converge, react and respond to disasters, in the same way as these disparate groups assembled (Quarantelli and Dynes, 1977; Britton, 1988, 1991). Other works from this research stream theorised on the concepts of formal, organised response, collective behaviour and role enactment. For instance, Dynes (1970) as cited in Webb (1999) argues that for a complete understanding of organisational response to disasters, one needs to understand the nature of the organisation itself. As such, he postulates a typology called DRC (Disaster Research Centre). The typology classifies organisations according to task and structure. This type of task could be either regular or non-regular, and he then classified these structures as old or new. From that classification, Dynes (1970) categorised organisations as Type I, II, III or IV. For example, Type I or established organisation (such as police, fire, and ambulance) with the characteristics of an existing (old) structure carrying out regular tasks during a response operation. Type II or expanding organisations (i.e. Red Cross) is characterised with carrying out regular tasks but with the new structural procedure. Type III or extending organisations have an existing (old) structure but undertake non-regular tasks in the event of a disaster. Lastly, a Type IV organisation, which is also known as an emergent organisation, is characterised by a new structure and always-undertaking non-regular tasks. See Table 2 for more details.

Table 2: DRC (Disaster Research Centre) Typology

\begin{tabular}{|l|l|l|l|}
\hline $\begin{array}{l}\text { Organisational } \\
\text { categorises }\end{array}$ & Description & $\begin{array}{l}\text { Examples of } \\
\text { Organisations }\end{array}$ & DRC Typology \\
\hline Type I & $\begin{array}{l}\text { Established } \\
\text { organisation }\end{array}$ & $\begin{array}{l}\text { Police, Fire, and } \\
\text { Ambulance services }\end{array}$ & $\begin{array}{l}\text { Existing (old) structure } \\
\text { while carrying out } \\
\text { regular tasks }\end{array}$ \\
\hline Type II & $\begin{array}{l}\text { Expanding } \\
\text { organisations }\end{array}$ & $\begin{array}{l}\text { Red Cross, Salvation } \\
\text { Army, Humanity Road, } \\
\text { Standby Taskforce }\end{array}$ & $\begin{array}{l}\text { New structural } \\
\text { procedures but with } \\
\text { regular tasks }\end{array}$ \\
\hline Type III & $\begin{array}{l}\text { Extending } \\
\text { organisations }\end{array}$ & $\begin{array}{l}\text { Public or non-profit } \\
\text { organisations such as } \\
\text { sporting clubs, logging } \\
\text { company or Religious } \\
\text { groups }\end{array}$ & $\begin{array}{l}\text { Existing (old) structure } \\
\text { but undertake non- } \\
\text { regular tasks }\end{array}$ \\
\hline Type IV & Emergent organisation & $\begin{array}{l}\text { Spontaneous and transient } \\
\text { in nature like Virginia } \\
\text { Tech Facebook group }\end{array}$ & $\begin{array}{l}\text { The new structure and } \\
\text { always-undertaking non- } \\
\text { regular tasks }\end{array}$ \\
\hline
\end{tabular}

Researchers in this field also provide theoretical advances in the concept of collective behaviour, social solidarity and convergence phenomena (Fritz and Mathewson, 1957). Interestingly, Information Systems researchers with a specific interest in the crisis informatics field observed that the difference between offline and online convergence behaviour is in the immediacy in which information and 
people converge, as well as the distance from which people can contribute to the relief effort (Hughes et al., 2008). Likewise, Fritz and Mathewson (1957) observed that in the aftermath of every disaster, there is always a convergence of people, information and resources (material). In explaining the nature of the people that converge on the disaster site, the authors classified these 'convergers' as 'returnees', 'anxious', 'helpers', 'curious', and the 'exploiters'. Later, Kendra and Watchtendorf (2003) as cited by Hughes et al. (2008) added 'mourners' and 'supporters'. Using the same sociological constructs of Fritz and Mathewson's (1957) social convergence behaviour, Hughes et al. (2008) conclude that the difference is only in speed and geography. Groups that spontaneously converge as bystanders during a disaster and disappear shortly, are referred to as emergent groups because their advent and actions are extempore and therefore, exclusive to the catastrophe (Kreps and Bosworth, 2007). Disaster sociologists describe their collective behaviour as unaffiliated, convergent and spontaneous (Kreps and Bosworth, 2007).

To understand emergent groups, Stallings and Quarantelli (1985) investigate their roles and their implications in the emergency management process during disasters. The authors observed that these emergent groups are informal, and evolved based on the notion that emergency management organisations are nowhere near the disaster scene, or those present are overwhelmed or incapable of providing services to the disaster-affected communities. They also characterised these groups as lacking in the formalisation of structures and tasks as well as tradition. The groups also take the form of 'damage group', 'search and rescue group' or 'coordination group' depending on the circumstances.

While the preceding sociological depiction of emergent groups appears before the advent of web 2.0, such type of emergence is also prevalent in the virtual world. Crisis informatics literature documents the appearance of virtual emergent groups during the July 2005 London bombings, Hurricane Katrina (Liu et al., 2008), the Virginia Tech event (Palen et al., 2009) as well as the 2007 Southern California wildfires (Sutton, Palen and Shklovski, 2008). Accordingly, Stallings and Quarantelli (1985) postulate that emergent groups will always appear in any disaster-impacted environment. They argue that such an appearance is inexorable, obvious, neither necessarily dysfunctional nor conflictive and its obliteration by any groundwork is something next to impossible. The study, therefore, recommends the need for recognition publicly of these groups by those in authority, as well as the need for linking their activities into the network of the organised response system.

Majchrzak, Jarvenpaa and Hollingshead (2007) used Transactive Memory System (TMS) theory - a postulation about knowledge management and coordination in groups - to provide insight into how this virtual emergent response team coordinates their activities using technology and available resources. Long before the use of TMS theory, Kreps and Bosworth (2007) theorised the concept of 
collective behaviour. The authors derived their proposition from the DRC postulation of the organised response. They suggest that "formal organising starts with a clear understanding about the domain [D] and tasks [T] (i.e. what is being done, by whom, and how) before resources [R] are mobilised, and activities [A] take place (Majchrzak, Jarvenpaa, and Hollingshead, 2007, p. 300). Therefore, according to this proposition, established groups exhibit formal organising behaviour while emergent groups exhibit collective behaviour. The difference is, "with collective behaviour, activities [A] take place and resources $[R]$ are mobilised before such understanding exist. The sequencing of the organisational element is A - R - T - D” (Majchrzak, Jarvenpaa and Hollingshead, 2007, p. 300)

\section{Public organisations}

Apart from the role of these emergent online groups, local management and public emergency organisations also take advantage of crowdsourcing in emergencies. These public organisations leverage crowdsourcing for information gathering and sense-making using open source tools and forums. For example, Heinzelman and Waters (2010) examine how the use of Ushahidi; an open crisis mapping software, helps relief organisations aggregate reports for food, water, shelter and medical care during emergency management operation. The findings revealed that organisations use the platform for authenticating and triaging high volumes of messages. An additional study also evaluates the potential use of open-source information in a crisis region of Iraq. Findings from the study claim that by leveraging open source, they were able to source, format, and map a visual, cartographic structure of otherwise random information. Through such a process, they were also able to figure out the number of humanitarian organisations operating in Iraq with a listing of their thematic and geographical areas in the field. Their methodology enabled them to identify areas most recurrently experiencing security events. This method not only reveals the overall working environment within different parts of the country but also serve as a decision-making tool for donors and humanitarian aid agencies planning to deploy their personnel (Mubareka et al., 2005).

In addition to the use of crowdsourcing for information gathering and sense-making, these organisations are also leveraging it to increase their effectiveness in providing time-critical media services. A study on the use of crowdsourcing by the Indonesian Agency for Meteorology concludes that the haste and reach of the government's tsunami early warnings would be significantly less without citizens' online and direct participation in rebroadcasting the message. The active part played by volunteer citizens, as claimed by the authors, increased the agency's efficiency in reaching over 4 million people within 15 minutes of the earthquake (Chatfield, Scholl and Brajawidagda, 2013).

\section{Digital Volunteer Communities (DVCs)}

The literature on permanent digital volunteer communities revolves around understanding their classification, activities, impacts, collaboration alongside its associated challenges with emergency management organisations and relief agencies. Van Gorp's (2014) study explores different types of 
digital volunteer communities and categorises them based on their functions, expertise and interest. The author classified these communities into crisis mapping communities, software and development communities, expert network communities and social media and data aggregation communities (ibid). Communities such as crisis mapping communities include, among others, Humanitarian OpenStreet Map, Standby Task Force, Crisis Mappers, GEOCAN, GisCorps and Map Action. Software platforms and development communities include organisations such as Sahana Software Foundation, Frontline SMS and Ushahidi. Expert network communities comprise organisations such as Crisis Commons, Random Hacks of Kindness, Geeks Without Bounds and Data Kind. Social media and data aggregation communities include volunteer organisations such as Humanity Road and ICT4Peace. Other studies related to digital volunteer communities focus their attention on understanding their activities and associated impact within the humanitarian ecosystem. For example, Meier (2011) provides insight into the effects of crisis mapping communities with regards to how they mobilise resources and provide information as a form of aid during disasters. The study underscores how crisisaffected communities are gradually taking a critical role as a source of digital information.

Likewise, Starbird and Palen (2013) explored the trajectory of Humanity Road right from its inception as an emergent group to its transmutation as an established group. The study sheds light on its information processing activities during mass disruption to its quest to standardise digital disaster response work.

Past studies such as the work of Sabou and Klein (2016) investigate the role of digital volunteer communities in augmenting the practice of formal humanitarian organisations. The study provides insights into how they provide vital situational awareness information for decision making. The work of Hughes and Tapia (2015), provides a more informed insight with regards to socio-technical impact between professional responders and digital volunteers. The study suggests ways to improve collaboration and coordination. The suggestion proposed by the authors include incorporating mediators, revisiting trust, emergency policy and process changes, a bounded social environment, digital volunteer data as context, and computational solutions (ibid). Other studies identified several barriers to coordination between digital volunteers and emergency management organisations and relief agencies. Some of these barriers include governance structure, technical and information management capabilities, ethical and security challenges as well as the legal implications of digital volunteers (Sabou and Klein, 2016; Meier, 2011). Others are the difference in organisational structure (hierarchical versus flat), philosophies and corporate culture, privacy, data ownership, liability and security (Weinandy, 2016).

Apart from understanding their motivations, coordination mechanisms and tools, Meier (2011) brings the discourse of digital volunteer communities from the blogosphere and listserv to the mainstream research community. His study assesses the impact of crisis mapping technology through the lens of 
the humanitarian crises in Haiti, Russia, Libya and Somalia. Meier's (2011) findings suggest that digital humanitarian intervention helped in providing shared situational awareness, decision making, self-organising and tendency to save lives. As novel as this study with its rare insights is, it is not clear whether the impact provided by these mapping communities is generalisable to other communities such as data aggregation communities, software platforms and development communities and expert network communities. However, the study provides an exciting benchmark for comparative analysis of impacts on various online volunteer groups.

As these communities begin to interface within the ecosystem of humanitarian clusters, barriers to collaboration start to emerge. These barriers include; volunteer-based problems; disaster response and humanitarian relief organisation-based challenge as well as mutually shared challenges.

Regarding volunteer-based challenges, the most common pressing issues in their communities have to do with volunteer management. As part of their continuous improvement programmes, these communities usually invest their effort in training volunteers so that over time they will become highly skilled, well-experienced and trusted. Suddenly, some of the volunteers that receive such training disappear without prior notice or informing the organisations about their intention to withdraw. With such kind of sudden withdrawal, these organisations struggle with the 'institutional memory vacuum' created by these 'deserting' volunteers. While research dealing with this type of issue is at its infancy, some scholars hypothesise that volunteers usually disappear due to burnout, psychological stress, and lack of engagement and recognition as part of the sociological explanation for this volunteer instability (Meier, 2011; Van Gorp, 2014; Weinandy, 2016). However, it is yet unclear how researchers and practitioners are tackling these issues.

Concerning the second barrier, while digital humanitarians are struggling with volunteer management and loss of 'institutional memory' issues, formal and traditional humanitarian organisations are also not insulated from such challenges. For instance, some of the challenges faced by formal and traditional organisations relate to the dearth of workforce and policy guidelines to deal with this 'unnecessary addition' to their system (Hiltz, Kushama and Plotnick, 2014; Tapia and Moore, 2014). Their lack of workforce and policy guidelines offers a window for collaboration, but their organisational culture demands that humanitarian response be guided by standard operating procedures, which sometimes contradicts the philosophy of the digital volunteer communities' operations.

Finally, it is instructive to note that literature from IS, disasters, sociology and organisational studies is replete with associated challenges that bedevil the interfacing of these organisations with one another. Before the advent of web 2.0 and mobile technologies, disaster sociologists summarised 
studies conducted by DRC on problems associated with organisational behaviour in the context of disaster management (Quarantelli, 1988). The study finds information flow, the exercise of authority and coordination as the significant issues experienced by organisations responding to disasters. Specifically, the author shows that the organisational problems associated with the communication process and information flow are intra-organisational, inter-organisational, from organisation to the public, from the government to organisations, and within systems of organisations. The author also counts personal exhaustion, the organisational authority of conflict, organisational domain conflict and inter-organisation jurisdictional issues as the biggest problems in organisational decision-making. The study finding also outlines the lack of inter-organisational consensus, strained coordination between disaster response organisations and impact of disaster magnitude as the main issues associated with coordination during disaster management.

While the other summarisation of DRC findings broadly identified communication process and information flow, the exercise of authority and decision making as well as coordination, recent studies associated with digital volunteer communities nearly mirror the same thing, with some few exceptions. In comparison with DRC's research findings, our review explores digital volunteer communities' crisis management approach and issues associated with its response operation. Findings from our research clustered around coordination and data management issues. IS literature is replete with concern on the use of crowdsourced data by digital volunteer communities while responding to emergencies (e.g. Tapia, Moore and Johnson, 2013). Such concerns centred on data trustworthiness, quality and credibility as well as issues related to ethics, privacy, security and intellectual property (ibid). In a related study that uses the concept of articulation to explore the coordination of humanitarian response between digital volunteers as well as formal humanitarian response and disaster relief organisations, Hughes and Tapia (2015) identified data quality, credibility and organisational need and fit as the main barriers to collaboration. The study suggests the use of mediators, revisiting trust and use of bounded social media environment as an alternative approach to address the information quality issue. They also suggest the use of mediators, policy and process change to overcome organisational need and fit, while the use of volunteers' data as ambient, and the computational method, can serve as a solution to the trust issue. Tapia and Moore (2014) add another dimension to the data management issue by concluding that aspects of crowdsourced information had extended the limits of data accuracy and credibility to that of operational concerns.

Related to the above challenges are the issues of communication, institutional routines and social processes (Sabou and Klein, 2016). Adding another dimension to understanding disaster management issues, Rozakis (2007) uses cultural theory and risk perception to discuss the cultural context of disaster management. The author combines this theoretical analysis with a case study of the King Crossfire incident of 1987. The study reveals that cultural differences such as training, hierarchy and authority, communication, decision-making, and secrecy among emergency management 
organisations were the main barriers affecting holistic inter-organisational coordination of disaster response. For emergency management organisations to reduce the impact of cultural differences, they have to incorporate isomorphic and active learning in their interoperability framework.

\section{Review observations}

We now reflect on our engagement with the literature and discuss pertinent observations that we believe need attention from the research community.

To date, both IS and disasters scholars have documented ease of use, convenience, affordability and availability as some of the factors prompting the public to use social media during emergencies. Existing literature does not provide sufficient scholarly work on the role of mobile-based messaging applications such as WeChat, Whatsapp, Jott and Viber in emergency management. It is surprising that even though credible media organisations like the $\mathrm{BBC}^{2}$ have used messaging application such as WhatsApp during the Ebola epidemic and are using them for crowdsourcing news in hard to reach areas, scholars have not focused on examining this phenomenon as to what roles they are playing. Issues related to barriers, diffusion, ease of use, and technology itself would indeed be a promising field to examine.

On the literature related to social media, it is worth noting that recent humanitarian emergencies such as the Nepal earthquake and Ghana flooding proved social media to be a potent reporting tool. These incidences attested Facebook, YouTube, Instagram and Twitter as tools with multidimensional organising potentials. The ability of these social media technologies to help in raising global awareness and provide tools for locating missing people is an excellent potential ${ }^{3}$. These social media platforms also enable the world community to provide funds and inform relatives of the whereabouts of their families. A typical example of the potency and powerful propagation mechanism of social media is how it enabled donors to contribute $\$ 8$ million to the Red Cross for Haiti within 48 hours ${ }^{4}$. However, there has been a little discussion by the IS community that gives a neutral and scholarly narrative on the reality of these potentials. These researches provide only anecdotal instances to support the role of social media in emergencies (Jung and Moro, 2014). There is, a need for further empirical studies in this regard. Such studies should aim to determine to what extent Google Person Finder, Facebook Safety Checks and similar social crowdsourcing and crowdfunding tools aid victims, communities and aid agencies in managing humanitarian emergencies.

\footnotetext{
${ }^{2}$ http://www.bbc.co.uk/news/world-africa-29573964

${ }^{3}$ http://mashable.com/2015/04/30/facebook-donation-nepal/

${ }^{4}$ http://news.bbc.co.uk/1/hi/world/americas/8460791.stm
} 
Although crowdsourcing receives attention from both the IS and disaster communities, there is still a need for further research in the area of digital volunteer communities. It is instructive to note that scholars provide insights on how volunteers used social media tools to provide collective intelligence during emergencies (Vieweg et al., 2008). The literature is also replete with studies that deal with the roles of digital volunteer communities in collaboration, and others that looked at barriers (e.g. Van Gorp, 2014), debates and concerns regarding data quality, legal liability, security implications, intellectual property, ethical considerations, crisis mapping and the impact of digital volunteers on humanitarian organisations (Meier, 2011). However, despite growing concern from the United Nations, nation-states and global media sources, the field has not attracted academic interest on this 'unwelcome addition' to humanitarian systems and lacks deeper and richer grounding in theoretical work.

The review of these studies has revealed gaps in the use of social media in emergencies. These gaps include:

- The shortage of a social media policy framework for practitioners such as emergency management organisations and aid agencies that provide a blueprint for the rules of engagement with the public, as well as emergent groups.

- The inability of the research community to provide evidence-based insights on whether some roles that social media play during emergencies are more central than others.

- There is a lack of proper training, tools and platforms to overcome the challenge of the prevalence of false information in the initial emergency report and the need to proffer solutions for such misinformation.

- There is an absence of field research and surveys that go beyond the use of a convenience sample by employing national samples as well as longitudinal studies that explore emergencies which cover both response as well as recovery.

- The shortage of relevant scholarly work on the emerging roles of mobile-based messaging applications such as WeChat, Whatsapp, Jott and Viber in emergency management.

\section{Conclusion}

This review provides insight into the use of social media in emergencies. The result of this work helps in identifying gaps, which include the lack of a social media policy framework, lack of training and proper tools for engagement, and the absence of field research and surveys, as well as longitudinal studies, that explore emergencies and cover both the response as well recovery. Our work has helped in identifying the lack of relevant scholarly work on the emerging roles of mobile-based messaging applications in emergency response and management. 
The study has also contributed to identifying 13 common issues that appear across disaster crisis management studies. These items comprise: trust, data credibility, organisational needs and fits, data quality, communication, organisational culture, ethical issues, privacy issues, legal issues, intellectual property, institutional routines and social process. By sorting and aligning these elements into DRC findings under three broad areas of the communication process and information flow, the exercise of authority and decision-making, and coordination, we realised that six elements fit into their findings. For example, under communication process and information flow, communication (Sabou and Klein, 2016) elements tally with DRC findings. Under the exercise of authority and decision-making, two features such as institutional routines and social process (Sabou and Klein, 2016) fit into DRC's categorisation. Again, three elements comprising operational issues (Tapia, Moore and Johnson, 2013; Tapia and Moore, 2014), organisational culture and organisational needs and fit (Hughes and Tapia, 2015) satisfied DRC's classification of coordination. However, the remainder of the seven common concerns in our study: intellectual property, data quality, data credibility, legal issues, ethical issues, privacy issues and trust (Hughes and Tapia, 2015; Van Gorp, 2014; Tapia and Moore, 2014; Tapia, Moore and Johnson, 2013; Office for the Coordination of Humanitarian Affairs (OCHA), 2013; Meier, 2011), did not match with any DRC categorisations. Taking a thoughtful and deeper look, we may conclude that all seven elements could come under one broad category: the data management issue. By identifying these seven elements, which are not in previous studies, we provide a unique contribution to social media studies in emergencies.

Future studies should determine to what extent Google Person Finder, Facebook Safety Checks and other social crowdsourcing and crowdfunding tools and platforms aid victims, communities and aid agencies in managing humanitarian emergencies. Such studies should look at understanding the role which disaster-affected communities play as first responders in any emergencies, as well as the emerging roles of mobile-based messaging applications in disaster emergency management. There is also a need for the development of frameworks and policies for collaboration between emergency management organisations and digital volunteer communities that will address the issues of trust, privacy, security and legal challenges. 
Appendix A: List of Journals

\begin{tabular}{|c|c|}
\hline Literature source and types & $\begin{array}{l}\text { Count of } \\
\text { Publication }\end{array}$ \\
\hline \multicolumn{2}{|l|}{ Blog } \\
\hline Verity Think & 1 \\
\hline \multicolumn{2}{|l|}{ Conference } \\
\hline 2012 IEEE Asia-Pacific Services Computing Conference & 1 \\
\hline 47th Hawaii International Conference & 1 \\
\hline $\begin{array}{l}\text { Proceedings of the Seventeenth Americas Conference on Information Systems (AMCIS } \\
\text { 2011) }\end{array}$ & 1 \\
\hline Proceedings of the Information Systems for Crisis Response and Management Conference & 8 \\
\hline Proceedings of the Pacific Asia Conference on Information Systems (PACIS 2016) & 1 \\
\hline $\begin{array}{l}\text { Proceedings of the } 2013 \text { Conference on Computer Supported Cooperative Work - CSCW } \\
\text { '13 }\end{array}$ & 1 \\
\hline $\begin{array}{l}\text { Proceedings of the Special Interest Group on Computer-Human Interaction (SIGCHI) } \\
\text { Conference on Human Factors in Computing Systems }\end{array}$ & 1 \\
\hline Hawaii International Conference on System Sciences (HICSS 2009) & 1 \\
\hline International Conference on Wirtschaftsinformatik (Wirtschaftsinformatik 2013) & 1 \\
\hline \multicolumn{2}{|l|}{ Journal } \\
\hline Communications of the ACM & 1 \\
\hline Computer Supported Cooperative Work (CSCW), & 2 \\
\hline Convergence & 1 \\
\hline Disasters & 2 \\
\hline First Monday & 3 \\
\hline Government Information Quarterly & 4 \\
\hline Information Systems Frontiers & 2 \\
\hline International Review of the Red Cross & 1 \\
\hline Journal of Information Systems Research & 1 \\
\hline Journal of Applied Communication Research & 1 \\
\hline Journal of Homeland Security and Emergency Management & 1 \\
\hline Journal of Information Privacy and Security & 1 \\
\hline Journal of Information Science & 1 \\
\hline
\end{tabular}




\begin{tabular}{|l|c|}
\hline Lecture Notes in Computer Science & 1 \\
\hline National Consortium for the Study of Terrorism and Responses to Terrorism & 1 \\
\hline Organization Science & 1 \\
\hline Social Science Computer Review & 1 \\
\hline The Information Society & 1 \\
\hline UN Chronicle & 1 \\
\hline Magazine & 1 \\
\hline Ars Technica & 1 \\
\hline Wired Magazine & \\
\hline Newspaper and Report & 1 \\
\hline $\begin{array}{l}\text { The Guardian and The London School of Economics and Political Science (joint } \\
\text { publication) }\end{array}$ & $\mathbf{4 9}$ \\
\hline United State Institute of Peace Publication (Special Report) & \\
\hline Total & \\
\hline
\end{tabular}




\section{References}

Boeder P (2002) Non-profits on e: how non-profit organisations are using the internet for communication, fundraising, and community building. First Monday 7(7).

Boughzala I, De Vreede T, Nguyen C and De Vreede GJ (2014) Towards a maturity model for the assessment of ideation in crowdsourcing projects. In: Proceedings of the 47th Hawaii International Conference on System Sciences, Waikoloa, HI, USA, 6-9 January 2014, pp. 483-490. IEEE. doi: 10.1109/HICSS.2014.67

Brabham DC (2012) Motivations for participation in a crowdsourcing application to improve public engagement in transit planning motivations for participation in a crowdsourcing application to improve public engagement in transit planning. Journal of Applied Communication Research 40(3): 307-28. doi: 10.1080/00909882.2012.693940.

Braun V and Clarke V (2006) Using thematic analysis in psychology. Qualitative Research in Psychology 3(2): 77-101.

Bright P (2011) How the London riots showed us two sides of social networking, Ars Technica.

Available at: https://arstechnica.com/tech-policy/2011/08/the-two-sides-of-social-networkingon-display-in-the-london-riots/ (accessed 20 July 2018).

Britton NR (1988) Organised behaviour in disaster: a review. International Journal of Mass Emergencies and Disasters 6(3): 363-395.

Britton NR (1991) Permanent disaster volunteers: where do they fit? Nonprofit and Voluntary Sector Quarterly 20(4): 395-414. doi: 10.1177/089976409102000404.

Campbell DA (2010) Stand by me: Organization founding in the aftermath of disaster. American Review of Public Administration 40(3), 351-369. doi: 10.1177/0275074009336205.

Chatfield AT, Scholl HJJ and Brajawidagda U (2013) Tsunami early warnings via Twitter in government: Net-savvy citizens' co-production of time-critical public information services. Government Information Quarterly 30(4): 377-386.

Cheong M and Lee VCS (2011) A microblogging-based approach to terrorism informatics: Exploration and chronicling civilian sentiment and response to terrorism events via Twitter. Information Systems Frontiers 13(1): 45-59.

Doan A, Ramakrishnan R and Halevy AY (2011) Crowdsourcing systems on the world-wide web. Communications of the ACM 54(4): 86-96. doi:10.1145/1924421.1924442

Dynes RR (1970) Organized Behavior in Disaster. Lanham, USA: Heath Lexington Books. 
Estellés-Arolas E and Gonza'lez-Ladro'n-de-Guevara F (2012) Towards an integrated crowdsourcing definition. Journal of Information Science 38(2): 189-200. doi: 10.1177/0165551512437638.

Fraustino JD, Liu B and Jin Y (2012) Social media use during disasters: a review of the knowledge base and gaps. Science and Technology Directorate, US Department of Homeland Security. College Park, MD: START.

Fritz CE and Mathewson JH (1957) Convergence behavior in disasters: A problem in social control A special report prepared for the Committee on Disaster Studies. National Academy of Sciences, National Research Council. Washington.

Geiger D, Seedorf S, Schulze T, Nickerson RC and Schader M (2011) Managing the Crowd: Towards a Taxonomy of Crowdsourcing Processes. In: Proceedings of the Seventeenth Americas Conference on Information Systems (AMCIS), Detroit, Michigan, USA, 4-7 August 2011, pp. 1-11. Association for Information Systems

Haythornthwaite C (2009) Crowds and communities: Light and heavyweight models of peer production. In: Proceedings of the 42nd Hawaii international conference on system sciences, Big Island, Hawaii, USA, 5-8 January 2009, pp. 1-10. IEEE.

Heinzelman J and Waters C (2010) Crowdsourcing crisis information in disaster-affected Haiti. Washington, DC: US Institute of Peace. Available at: https://www.files.ethz.ch/isn/121995/SR252\%20\%20Crowdsourcing\%20Crisis\%20Information\%20in\%20Disaster-Affected\%20Haiti.pdf

Hetmank L (2013) Components and Functions of Crowdsourcing Systems-A Systematic Literature Review. In: Proceedings of the 11th International Conference on Wirtschaftsinformatik, Leipzig, Germany, 27th February - 1st March 2013, pp. 55-69.

Hiltz SR, Kushma JA and Plotnick L (2014) Use of Social Media by US Public Sector Emergency Managers: Barriers and Wish Lists. In: Proceedings of the 11th International Information Systems for Crisis Response and Management (ISCRAM) Conference, University Park, Pennsylvania, USA, 18-21 May 2014, pp. 602-611.

Houston J B et al. (2015) Social media and disasters: a functional framework for social media use in disaster planning, response, and research. Disasters 39(1): 1-22. doi: 10.1111/disa.12092.

Howe J (2006) The rise of crowdsourcing. Wired magazine 14(6): 1-4.

Hughes AL and Tapia AH (2015) Social media in crisis: when professional responders meet digital volunteers, Journal of Homeland Security and Emergency Management 12(3): 679-706. doi: 10.1515/jhsem-2014-0080. 
Hughes AL, Palen L, Sutton J, Liu SB and Vieweg S (2008) Site-seeing in disaster: An examination of on-line social convergence. In: Proceedings of the 5th International Information Systems for Crisis Response and Management (ISCRAM) Conference, Washington, DC., 4-7 May 2008 , pp. 44-54.

Hwang YC, Yuan ST and Weng JH (2011) A study of the impacts of positive/negative feedback on collective wisdom — case study on social bookmarking sites. Information Systems Frontiers 13(2): 265-279.

Jomier J (2017) Open science-towards reproducible research. Information Services \& Use 37(3): 361367.

Jung JY and Moro M (2014) Multi-level functionality of social media in the aftermath of the Great East Japan Earthquake. Disasters 38(2): 123-143. doi: 10.1111/disa.12071.

Jung K and Park HW (2014) Citizens' social media use and homeland security information policy: Some evidences from Twitter users during the 2013 North Korea nuclear test. Government Information Quarterly 31(4): 563-573. doi: 10.1016/j.giq.2014.06.003.

Kaplan AM and Haenlein M (2010) Users of the world, unite! The challenges and opportunities of social media. Business Horizons 53(1): 59-68. doi: 10.1016/J.BUSHOR.2009.09.003.

Kendra JM and Wachtendorf T (2003) Reconsidering convergence and converger legitimacy in response to the World Trade Center disaster. Research in Social Problems and Public Policy 11(1): 97-122.

Kittur A, Nickerson JV, Bernstein M, Gerber E, Shaw A, Zimmerman J, Lease M and Horton J (2013). The future of crowd work. In: Proceedings of the 2013 ACM Conference on Computer Supported Cooperative Work, San Antonio, TX, USA, 23-27 February 2013, pp. 1301-1318.

Kohler, T., Fueller, J., Matzler, K., Stieger, D. and Füller, J., (2011). Co-creation in virtual worlds: The design of the user experience. MIS quarterly 35(3): 773-788.

Kreps GA and Bosworth SL (2007) 'Organizational adaptation to disaster', In Rodriguez H, Quarantelli EL and Dynes R eds. (ed.) Handbook of Disaster Research. New York, NY., pp. 297-315. Springer.

Larsson AO and Ågerfalk PJ (2013) Snowing, freezing ... tweeting? Organizational Twitter use during crisis, First Monday 18(6).

Lewis P, Newburn T, Taylor M, Mcgillivray C, Greenhill A, Frayman H and Proctor R (2011) Reading the riots: investigating England's summer of disorder. The Guardian and The London 
School of Economics and Political Science. London, UK. Available at:

http://eprints.1se.ac.uk/id/eprint/46297

Liu SB (2014) Crisis crowdsourcing framework: designing strategic configurations of crowdsourcing for the emergency management domain. Computer Supported Cooperative Work (CSCW) 23(4): 389-443. doi: 10.1007/s10606-014-9204-3.

Liu SB, Palen L, Sutton J, Hughes AL and Vieweg S (2008) In search of the bigger picture: The emergent role of on-line photo sharing in times of disaster. In: Proceedings of the 5th Information Systems for Crisis Response and Management (ISCRAM) Conference, Washington, DC., 4-7 May 2008, pp. 4-7.

Luna S and Pennock MJ (2018) Social media applications and emergency management: A literature review and research agenda. International Journal of Disaster Risk Reduction 28: 565-577. doi: 10.1016/j.ijdrr.2018.01.006.

Majchrzak A, Jarvenpaa SL and Hollingshead AB (2007) Coordinating expertise among emergent groups responding to disasters. Organization Science 18(1): 147-161. doi: $10.1287 /$ orsc. 1060.0228 .

Marjanovic S, Fry C and Chataway J (2012) Crowdsourcing based business models: In search of evidence for innovation 2.0. Science and Public Policy. Oxford University Press 39(3): 318332.

McGrath K, Elbanna A, Hercheui M, Panagiotopoulos P and Saad E. (2012) Exploring the democratic potential of online social networking: The scope and limitations of e-participation. Communications of the Association for Information Systems 30(16): 239-254.

Meier P (2011) New information technologies and their impact on the humanitarian sector. International Review of the Red Cross, 93(884): 1239-1263. doi: $10.1017 / \mathrm{S} 1816383112000318$.

Mills A, Chen R, Lee J and Raghav Rao H (2009) Web 2.0 emergency applications: How useful can Twitter be for emergency response? Journal of Information Privacy and Security 5(3): 3-26.

Morris L (2014) Contextualizing the power of social media: Technology, communication and the Libya Crisis, First Monday, 19(12).

Morris MR (2014) Social networking site use by mothers of young children. In: Proceedings of the 17th ACM conference on Computer supported cooperative work \& social computing, Baltimore, Maryland, USA, 15-19 February 2014, pp. 1272-1282.

Mubareka S, Khudhairy DA, Bonn F and Aoun S (2005) Standardising and mapping open-source 
information for crisis regions: the case of post-conflict Iraq. Disasters 29(3): 237-254.

Najah A and Jarboui A (2015) Crowd funding for financing innovative and social entrepreneurship: literature review. Journal of Business Management and Economics 3(6): 21-24.

Nogami T and Yoshida F (2014) Disaster myths after the Great East Japan Disaster and the effects of information sources on belief in such myths, Disasters 38(s2): s190-s205.

OCHA (2013) Humanitarianism in the Network Age. United Nations Publications. New York: OCHA.

Oh O, Agrawal M and Rao HR (2011). Information control and terrorism: Tracking the Mumbai terrorist attack through twitter. Information Systems Frontiers 13(1): 33-43.

Palen L, Vieweg S and Anderson KM (2010) Supporting "Everyday Analysts" in safety- and timecritical situations. The Information Society 27(1): 52-62. doi: 10.1080/01972243.2011.534370.

Palen L, Vieweg S, Liu SB, Hughes AL (2009) Crisis in a networked world: Features of computermediated communication in the April 16, 2007, Virginia Tech event. Social Science Computer Review 27(4):467-80.

Panagiotopoulos P, Bigdeli AZ and Sams S (2014) Citizen--government collaboration on social media: The case of Twitter in the 2011 riots in England. Government Information Quarterly. 31(3): 349-357.

Poblet M, Garca-Cuesta E and Casanovas P (2014) Crowdsourcing tools for disaster management: A review of platforms and methods, Lecture Notes in Computer Science (including subseries Lecture Notes in Artificial Intelligence and Lecture Notes in Bioinformatics), 8929(Ccc), 261-274. doi: 10.1007/978-3-662-45960-7.

Putnam, L. (2002) By choice or by chance: How the Internet is used to prepare for, manage, and share information about emergencies. First Monday 7(11).

Qin Z, Cai J and Wangchen HZ (2015) How rumors spread and stop over social media: A multilayered communication model and empirical analysis. Communications of the Association for Information Systems 36(1)20: 369-391. doi.org/10.17705/1CAIS.03620

Quarantelli EL and Dynes RR (1977) Response to social crisis and disaster. Annual Review of Sociology 3(1): 23-49. doi: 10.1146/annurev.so.03.080177.000323.

Reuter C and Kaufhold MA (2018) Fifteen years of social media in emergencies: a retrospective review and future directions for crisis informatics. Journal of Contingencies and Crisis Management 26(1): 41-57. doi: 10.1111/1468-5973.12196. 
Rheingold H (2007) Smart mobs: The next social revolution. New York: Basic Books.

Rozakis M (2007) The cultural context of emergencies: Seeking for a(n) holistic approach on disaster management. Disaster Prevention and Management 16(2): 201-209. doi.org/10.1108/09653560710739522

Sabou J and Klein S (2016) How Virtual and Technical Communities Can Contribute to U.N. Led Humanitarian Relief Operations - Boundary Spanning and The Exploration of Collaborative Information Practices, In: Proceedings of the Pacific Asia Conference on Information Systems-IT Governance for Future Society, Chiayi, Taiwan, 27 Jun - 1 Jul 2016, p. 17.

Schmierbach M and Oeldorf-Hirsch A (2012) A little bird told me, so I didn't believe it: Twitter, credibility, and issue perceptions. Communication Quarterly 60(3): 317-337.

Stallings RA and Quarantelli EL (1985). Emergent citizen groups and emergency management. Public Administration Review 45: 93-100.

Starbird K (2012) What "Crowdsourcing" Obscures: Exposing the Dynamics of Connected Crowd Work during Disaster, arXiv preprint arXiv:1204.3342.

Starbird K and Palen L (2011) "Voluntweeters": Self-Organizing by Digital Volunteers in Times of Crisis, In: Proceedings of the Special Interest Group on Computer-Human Interaction (SIGCHI) Conference on Human Factors in Computing Systems CHI 2011, Vancouver, BC, Canada, 7-12 May, 2011, pp. 1071-1080.

Starbird K and Palen L (2013) Working and sustaining the virtual "Disaster Desk". In: Proceedings of the 2013 Conference on Computer Supported Cooperative Work - CSCW'13. New York, USA: ACM Press, pp. 491-502. doi: 10.1145/2441776.2441832.

Starbird K, Muzny G and Palen L (2012) Learning from the crowd: collaborative filtering techniques for identifying on-the-ground Twitterers during mass disruptions. In Proceedings of 9 th International Conference on Information Systems for Crisis Response and Management (ISCRAM) Vancouver, Canada, 22-25 April 2012, pp. 1-10.

Stiver A, Barroca L, Minocha S, Richards M and Roberts D (2015) Civic crowdfunding research: Challenges, opportunities, and future agenda. New Media \& Society 17(2): 249-271.

Sutton, J. N., Palen, L. and Shklovski, I. (2008) Backchannels on the front lines: Emergency uses of social media in the 2007 Southern California Wildfires. In: Proceedings of the 5th International Information Systems for Crisis Response and Management (ISCRAM) Conference, Washington, DC., 4-7 May 2008, pp. 1178-1204.

Tapia AH and Moore K (2014) Good enough is good enough: overcoming disaster response 
organizations' slow social media data adoption, Computer Supported Cooperative Work: CSCW: An International Journal 23(4-6): 483-512. doi: 10.1007/s10606-014-9206-1.

Tapia AH, Moore K and Johnson NJN (2013) Beyond the Trustworthy Tweet: A Deeper Understanding of Microblogged Data Use by Disaster Response and Humanitarian Relief Organizations, In: Proceedings of the 10th International Information Systems for Crisis Response and Management (ISCRAM) Conference, Baden-Baden, Germany, 12-15 May 2013, pp. 770-779. doi: 10.1145/1978942.1979102.

Van Der Meijden MJ, Tange HJ, Troost J and Hasman A (2003) Determinants of success of inpatient clinical information systems: a literature review. Journal of the American Medical Informatics Association 10(3): 235-43. doi: https://doi.org/10.1197/jamia.M1094

Van Gorp AF (2014) Integration of volunteer and technical communities into the humanitarian aid sector: Barriers to collaboration. In: Proceedings of the 11th International Information Systems for Crisis Response and Management (ISCRAM) Conference, University Park, Pennsylvania, USA, 18-21 May 2014, pp. 622-631.

Vieweg S, Palen L, Liu SB, Hughes AL and Sutton JN (2008) Collective Intelligence in Disaster: Examination of the Phenomenon in the Aftermath of the 2007 Virginia Tech Shooting. Boulder, CO: University of Colorado.

Vom Brocke J, Simons A, Riemer K, Niehaves B, Plattfaut R and Cleven A (2015) Standing on the shoulders of giants: Challenges and recommendations of literature search in information systems research. Communications of the Association for Information Systems 37(1): 9.

Warr W (2008) Social software: fun and games, or business tools? Journal of Information Science 34(4): 591-604. doi/abs/10.1177/0165551508092259

Wattal S, Schuff D, Mandviwalla M, and Williams CB (2010) Web 2.0 and politics: the 2008 U.S. Presidential election and an e-politics research agenda. MIS Quarterly 34(4): 669-688.

Webb GR (1999) Individual and Organizational Response to Natural Disasters and Other Crisis Events: The Continuing Value of the DRC Typology. Paper presented at the annual meeting of the Eastern Sociological Society, Paper \#277, University of Delaware Disaster Research Center, Boston, Massachusetts.

Webster J and Watson R T (2002) Analyzing the past to prepare for the future: Writing a literature review. MIS Quarterly pp. xiii--xxiii.

Weinandy TJ (2016) Volunteer and technical communities in humanitarian response: lessons in digital humanitarianism from Typhoon Haiyan. UN Chronicle 53(1): 29-30. 
Wolfswinkel JF, Furtmueller E and Wilderom CPM (2013) Using grounded theory as a method for rigorously reviewing literature. European Journal of Information Systems 22(1): 45-55. doi: 10.1057/ejis.2011.51.

Yu Z, Zhang D, Yang D and Chen G (2012) Selecting the Best Solvers: Toward Community Based Crowdsourcing for Disaster Management, In: Proceedings of the 2012 IEEE Asia-Pacific Services Computing Conference, Guilin, China, 6-8 December 2012, pp. 271-277. IEEE. doi: 10.1109/APSCC.2012.20

Zwass V (2010) Co-creation: toward a taxonomy and an integrated research perspective. International Journal of Electronic Commerce 15(1): 11-48. doi: 10.2753/JEC1086-4415150101.

\begin{abstract}
About the authors
Dr Najeeb Gambo Abdulhamid holds a $\mathrm{PhD}$ in Computer Science from Brunel University London and an MSc in Information Systems from the prestigious University of Aberdeen in Scotland (UK). He is a lecturer in the Department of Computer Science Jigawa State Polytechnic Dutse, Nigeria. Najeeb research interest revolves around ICT4D, social and collaborative computing and the emerging field of crisis informatics as well as the sociology of the internet. He published papers in the Journal of Web of Science, and Lecture Notes in Computer Science among others.
\end{abstract}

Dr Daniel Azerikatoa Ayoung is a lecturer and researcher in Information Systems at the Bolgatanga Polytechnic, Ghana. He holds an MSc and a PhD in Information Systems. His specific research interest is in the implementation of ICT4D initiatives and Information and Knowledge Management in developing countries. His current focus is on IT/ICT implementation and user adaptations in the work environment. Email: daniel.ayoung@bpoly.edu.gh

Dr Armin Kashefi is a lecturer in Business Computing in the Department of Computer Science, Brunel University London. He has an MSc and $\mathrm{PhD}$ in Information Systems Management. His research interests include people and technology, information systems for crisis response and management (ISCRAM) and information and communication technologies (ICTs) and development. He participated in two Horizon 2020 EU projects (TANDEM and Sci-GaIA) which aim to support dialogue between the EU and African Research and Educational Networks, with special attention to Western and Central Africa region. His current research continues to explore sustainable e-Infrastructures in Africa as well as modelling and analysis of complex systems using discrete simulation modelling. Email: armin.kashefi@brunel.ac.uk Tel: +44 (0)1895268180 
